MISS FIELDE, an American missionary lady stationed at Swatow, has, it is stated, completed a voluminous dictionary of the Swatow dialect, which will be published shortly.

THE additions to the Zoological Society's Gardens during the past week include a Feline Dourocouli (Nyctipithecus voci. ferans \&) from Columbia, presented by Mr. H. H. Thiele; an Indian Civet (Viverricula indica $९$ ) from India, presented by Capt. Wilson; two Squirrel-like Phalangers (Belideus sciureus) from Australia, presented by A. Pretyman; a Vulpine Phalanger (Phalangista vulpina) from Australia, presented by Mr. J. E. Dothie ; an Australian Crow (Corvus australis) from Australia, presented by Mrs. A. H. Jamrach; a Nicobar Pigeon (Calanas nicobarica) from the Philippine Islands, presented by Mr. Hugh Low ; two Common Gulls (Larus canus), British, presented by Mr. C. W. Jervis Smith; a Spotted Mud Frog (Pelodytes punctatus) fiom the South of France, presented by Mr. H. P. Cambridge; a Cape Ant Bear (Orycteropus capensis), twelve Derbian Zonures (Zonurus derbianus) from South Africa, two Canadian Beavers (Castor canadensis of $\&$ ) from Canada, a Viperine Snake (Tropidonotus viperinus) from North Africa, a Tree Boa (Corallus hortulanus) from South America, purchased; a Hairy-footed Jerboa (Dipus hirtepes) from Arabia, a Simun's Dwarf Jerboa (Dipodillus simoni) from Algeria, received in exchange; a Japanese Deer (Cervus sika of), a Hybrid Syrian Wild Ass (between Equus hemippus of and Equus onager $\$$ ), an Impeyan Pheasant (Lophophorus impeyanus), four Amherst's Pheasants (Thaumalea amherstic), bred in the Gardens.

\section{ON THE CAUSES OF GLACIER MOTION}

THE question of the causes which produce the movement of glaciers, which was at one time so eagerly discussed, would appear to have slumbered for the last ten years. Thi; cannot be said to arise from the fact that a perfectly satisfactory theory has been developed, and recognised as such by all inquirers. The ambiguous allusion to the subject in Sir John Lubbock's presidential address to the British Association is an evidence that such certainty has not been attained. It is indeed generally supposed that the fact of the melting-point of ice being lowered by pressure is somehow at the root of the matter; but a full explanation of the origin of this pressure in the case of glaciers and of the mechanical features of the problem has yet to be given. I may therefore be pardoned if I draw attention to a different solution, proposed not by myself but by one of the greatest of English mechanicians. My apology for doing so is that I approach the question as an engineer, not as a physicist; and that it is in its essence, as will be shown immediately, a mechanical rather than a physical problem.

The following are leading facts of glacier-motion which must be accounted for by any valid theory on the subject:-

(I.) The phenomena of the movement of a glacier are simply those of a solid body in a state of flow.

(2.) The present glaciers of Switzerland and Norway, which are the only ones which have been critically examined, are mere shrunken fragments of the glaciers of the Great Ice Age. To take one instance, the present glacier of the Rhone is about 6 miles long and perhaps 500 feet deep; but the old glacier of the Rhone, which abutted against the Jura, was 120 miles long, and mast have been 2000 to 3000 feet deep. The movement of such glaciers as this must also be accounted for in any satisfactory theory.

(3.) The glaciers of the present day are not confined to the temperate region; they are found in much larger numbers and of much greater size in the Arctic regions.

(4.) Both in the temperate and in the Arctic regions glaciers move in winter as well as in summer, and by night as well as by day.

That a glacier is in a state of flow was first proved by Forbes, and has since been confirmed by the measurements of Tyndall and others. Whilst the whole mass moves downwards, the top moves faster than the bottom and the sides than the middle; the upper layers must therefore be continually shearing over the

I Paper by Waiter R. Browne, M.Inst.C.E., read at the Royal Society, June $\mathrm{r}_{5}, \mathrm{r} 882$ lower, and the medial over the lateral. A glacier, being a body in a state of flow, must move under the influence of forces powerful enough to overcome its resistance, and so produce this condition.

The general phenomena of the motion of a glacier are exactly reproduced when a viscous body moves through a channel under the influence of its own weight. We have therefore first to inquire whether the shearing resistance of ice is sufficiently low to enable us to regard a glacier as a viscons mass.

The only experiments known to me on the shearing resistance of ice, are tho e of Moseley (Phil. Mag., January, 1870). He found that, with pressures from IOo to IIo lbs. per square inch, cylinders of ice sheared slowly across the two planes in contact, sliding over each other without losing continuity. The distance sheared through was about five-eighths of an inch in half an hour. A 1 ad of 119 lbs. per square inch was sufficient to shear through a cylinder of $I_{2}^{\frac{1}{2}}$ inches in diameter in two to three minutes. From these experimen!s it would appear that the lowest shearing stress which will cause ice to flow is about Ioo lbs. per square inch; but sufficient time was not allowed in the experiments to make this a matter of certainty.

There is another way in which the shearing resistance of ice may be tested. In the case of a block of ice of vertical sides, gravity of course produces a shearing resistance along all planes passing through the base. Let $h$ be the height of such a block in feet, and consider the shearing force due to gravity on any square foot of a plane making an angle $\theta$ with the vertical. This shearing force is given by-

$$
\frac{\frac{w h \times h \tan \theta}{2} \times \cos \theta}{h \sec \theta}=\frac{w h}{2} \sin \theta \cos \theta .
$$

This expression is a maximum when $\theta=45^{\circ}$, and its value is then-

$$
\frac{w h}{4} \text {. }
$$

What is the greatest height at which a vertical cliff of ice will stand? I am not able to state this precisely, but it is very considerable. Mr. Whymper mentions crevasses in South America 300 feet deep. Cliff; of fully that height have been seen standing out of water in the case of icebergs, and as so small a part of an iceberg projects above water, these cliffs probably extend below to a considerable depth. Taking, however, only 300 feet for the value of $h$, or for the maximum height of an ice cliff, this would give about 30 lbs. per square inch as the lowest shearing force upon a plane of ice which would cause it to assume the condition of flow.

I et us now suppose a slacier of thickness $a$, lying upon a slope whose inclination to the horizontal is $\boldsymbol{\beta}$; then the force per square foot, tending to shear the ice at its junction with the slope, is clearly aw $\sin \beta$.

Suppo ing $\sin \beta$ to equal $\frac{1}{4}$, and that the shearing resistance is 30 lbs. per square inch, we get $a=$ about 290 . Hence we may say that a glacier lying on a slope of $\mathrm{I}$ in 4 will not move at all under its own weight unless it be at least 300 feet thick, and that, if it be more than this, the upper 300 feet will move as one solid mass, the part below alone representing the conditions of flow.

It is needless to say that there are hundreds of glaciers which are less than 300 feet thick, and which at $n$ o part of their course have a slope anything approaching $I$ in 4 .

We have now to show that the theories generally propounded for glacier action are all of them negatived by some of the foregoing considerations. These theories may be stated as follows :-

(r.) The glacier simply slides over its bed as a solid body. This is negatived by the fact that some parts move faster than others.

(2.) The glacier flows under the action of its own weight, exactly as a viscous body flows. This is the theory of Forbes. It is disproved by the facts given above, which show that even on a slope of I in 4 a glacier would not flow unless it was at least 300 feet thick.

(3.) The glacier moves by the crushing of its base. This has been disproved by Moseley's experiments, which showed that the crushing resistance of ice was considerably higher than the shearing resistance.

(4.) The glacier moves by the melting of its base. This is the theory of Hopkins. He placed a block of ice at $32^{\circ} \mathrm{F}$. on a slab at a small angle, and found that it slowly descended as it melted. On this view the bottom of the glacier must always 
be in a melting state. But glaciers are of all sizes and thicknesses, and they move in winter as well as summer. Bessels ("Die Amerikanische Nordpol Expedition," p. 398) measured the motion of an Arctic glacier (not apparently very thick), in the month of April, which is just when the winter cold would have sunk deepest, and found it considerable. Again in the Zeitschrift des deutschen Geologischen Gesellschaft, vol. xxxiii. p. 693, is an account of measurements of a Greenland glacier, both in winter and summer, which show that the motion in winter is only 20 per cent. less than in summer. It has been suggested to me that the interior heat of the earth may be sufficient to keep the bottom of the ice from freezing; but this cannot apply near the sides, where the ice is shallow, and the freezing of a very small strip on each side would be sufficient to keep the whole mass from descending. Moreover, this cause would apply to masses of snow as much as to ice. But it is known that masses of snow, though lying on steep slopes, do not descend in this way, even in summer, but melt away where they lie.

(5.) According to the theories of Tyndall, Croll, and others, the glacier moves not in the form of ice but of water. These theories are based on the known fact that the freezing point of ice is lowered by pressure. Hence it is supposed that certain parts of a glacier are continually being exposed to so much pressure that they melt. The water escapes downward, and the pressure being relieved it freezes again. The continuity of the glacier is further kept up by the process of regelation, according to which two pieces of ice, if placed in contact, form into one solid mass.

The advocates of this theory hardly seem to consider how very small the lowering of the freezing point is for any ordinary pressure. It is only $0075^{\circ}$ per atmosphere. In other words, it will require a pressure of 2000 lbs. per square inch to liquefy ice at $3 \mathrm{I}^{\circ}$ instead of $32^{\circ}$. This is equivalent to the weight of a column of ice about 5000 feet high. It is needless to ask whether such a pressure can exist within an ordinary glacier, while on the other hand glaciers undoubtedly move at temperatures far below freezing point-in the Arctic regions below zero.

It seems to be generally supposed that the pressure in the lower part of a glacier is due to the steeper upper portions : the glacier channel is spoken of as a mould, through which the ice is forced by pressure from behind. But in the upper glacier, slopes of ice or nevé are not uncommon at angles of $30^{\circ}$ or even more. Such slopes usually do not even touch the more level parts of the glacier below them, but are separated from them by a wide, deep crevasse callet a Bersschrund. Of this the well-known ice wall of the Strahleck is a conspicuous example. In other cases such slopes do not end in a glacier at all, but die away upon the mountain side. It is certain, therefore, that ice or $n \epsilon v e$ is able to maintain itself at a high angle upon its slope of rocks, and therefore cannot possibly exercise pressure upon the parts of the glacier far in advance of its foot. The fallacy of this idea may be further illustrated by referring, not to modern glaciers, but to those of the Great Ice Age. Can we suppose that the pressure of the snows about the sources of the Rhone was sufficient to drive that glacier down the valley to Martigny, round a sharp angle to the Lake of Geneva, through the bed of that lake, and on to the slopes of the Jura, a distance of more than 100 miles, in which the average slope was about I in 200 ; giving a propelling force per ton of ice of about 1 I l lbs. only?

All these theories have this in common, that they regard gravity as the sole and direct agent in the movement of glaciers, and the above considerations seem to prove that it is an agent far too weak for the work it has to do. ${ }^{1}$

The only other agent which has been suggested, or seems likely to be suggested, to account for the motion of glaciers, is heat. This suggestion, as is well known, is due to the late Canon Moseley, F.R.S., and was to some extent worked out by him in papers published in the Phil. Mag., 1869 and 1870.

The mode of operation, on this theory, is well known. Ice $i$ i here considered merely as a solid body, obeying the ordinary laws of expansion and contraction under differences of temperature. This it is known to do, the coefficient of linear expansion, for $\mathrm{I}^{\circ} \mathrm{F}$., being ${ }^{\circ} 00002856$ (Moseley, Phil. Mag., January, r870), which is very high. When a mass of ice, such as a glacier, suffers a rise in teinperature, either through conduction or radia.

I Ancther evidence against pressure from behind as a cause of motion is furnished by the very small size of many glaciers. Some of these. ntably those of the class called "glaciers remaniés," are only a few hundred yards long, and cannot be many feet deep. tion, it will expand; this expansion will take place mainly in the direction where movement is easiest, that is, down the valley. If from any cause the temperature falls, the glacier will again contract ; but since the expansion is assisted by gravity whilst the contraction is opposed by it, the latter will be somewhat less in amount than the former, and when the ice has returned to its original temperature, its centre of gravity will have moved a certain small distance down the valley. By such alternate expansions and contractions the glacier moves gradually from the top to the bottom of its course.

That variations of temperature do take place in a glacier cannot be doubted, whatever be the condition in which it lies. This granted, the fact that it should move in the way described appears to me no more surprising than that the sheets of lead on which Canon Moseley made his well-known experiments did so move; and that the motion thus produced is of the character which answers to all the facts of the case, so far as they are at present known, can, I believe, be established.

The controversy occaioned by Canon Moseley's articles was unfortunately terminated by his illness and death, before the matter had been fully cleared up. The main objections urged to his theory were two. The first was that a glacier is not one continuous body (as assumed by Canon Moseley in his mathematical investigation), but is broken up into many parts by crevasses. But in the first place, the assumption above men tioned is merely one of convenience, and not in the least necessary to the theory. A detached piece of ice would move in the same way as a glacier, or as the sheet of lead did in Canon Mo:eley's experiments. Secondly, if a glacier is anywhere divided in its whole thickness by a crevasse, this is absolutely fatal to the gravitation theories, since there can be no pressure between the portions above and below this division. The only possible explanation of crevasses, on these theories, is that they are due to the glacier bending over a convex part of its bed. In that case the bottom half will be in compression, and only the top half in tension, so that the crevasse cannot possibly extend more than half way through the thickness.

The second objection was that the conductivity of ice is low ; hence the effect of the heat would be confined to the layers near the surface, and could not account for the motion of the glacier as a whole. This objection does not seem to be confirmed by careful reflection upon the way in which such forces act. Let us suppose a glacier roo feet deep, of which each successive foot expands and contracts alike throughout, but adheres with a definite shearing resistance to the layers above and below. Let there be a rise in temperature, which does not extend beyond the uppermost ro feet. This layer will expand, and if it were free would expand to the full amount due to the increase in temperature. But its lower surface is not free. In expanding it will therefore drag the next layer after it, or in other words will cause it to expand also. The amount of expansion, however, will not be so great, because there will be a certain shearing extension at the plane of division between the two. The second layer will similarly cause an expansion in the third, and so on to the bottom. In consequence the energy which would all have been exerted on the top layer, had that been free, will be distributed over the whole of the layers; and the extension of the top layers will of course be much smaller than it otherwise would have been. Should the temperature then remain constant, the layers will retain their position, and adapt themselves to the new circumstances. If the temperature falls, the layers will contract, but from the now opposing effect of gravity they will not return to their original po ition. The top layer, which has extended furthest, will be the furthest below its original position; the second layer next and so on. If we suppose the layers to be indefinitely thin, we have the condition of things in an actua glacier. The ice in any vertical section will, on the whole, move down the slope, but the top will move faster than the middle, and the middle than the bottom, exactly as it is known to do. The same holds with regard to a horizontal section. At the sides the ice will be held back, not only by the friction, but also by the protuberances of the rock, which compel the ice to shear over them. Hence the velocity there will be retarded, and will be less than that in the middle, which is comparatively free.

A more important objection remains to be considered, which is this. On the present theory the motion at any point on the surface of a glacier will be not continuous, but oscillating alter nately downwards and upwards, and the net distance by which it has descended, say, in a day, will be a mere fraction of the total distance through which it has moved in that period. If 
so, this alternate motion ought to have been noticed in the various observations which have been made upon glaciers, and this does not appear to have been the case. But, in reply to this, it may be remarked that most of the observations have only given the net movement of points on the glacier during intervals of a day or more, and therefore would not show the oscillations. Again, such observations have always been at points near the end of a glacier. Now the variations in temperature of a glacier will be very different at different parts, and the motion of the end of the glacier will, to a great extent, show the average result of these different advances and retreats in different parts of the higher regions. This average result will, of course, be a steady progression down the valley, and the oscillatory movement at the end of the glacier may be so much masked by this as not to be readily observable. Lastly, it may be suggested as possible that a certain amount of expansion by heat may have the effect of giving a set to ice, so that it does not return to its original length when brought back to the same temperature. If this be so, the oscillations would be much less marked, and at the end of the glacier would probably be indistinguishable.

I may now draw attention to some phenomena of glacier action, which are explained by the heat theory, but which do not seem explicable on the gravitation theory.

(I.) It is well known that glaciers, when they emerge from a narrow gorge into a comparatively wide valley, spread out into a fan shape. The Rhone glacier is a well-known instance. A still better one is a small glacier in Norway, mentioned by Prof. Sexa, which spreads out to five or six times its previous width. Now the effect of gravity, acting on a mass as a whole, is to carry it in one single direction, that of the steepest slope. The only way in which gravity can produce such a spreading out is by the parts of the glacier shearing over each other in the manner of a viscous solid. But the phenomena of ice cliffs, as mentioned above, show that ice does not spread from this cause, so that the fact seems impossible to explain by gravitation alone. On the heat theory it is, of course, perfectly easy : the expansion and contraction will take place in all directions where there is freedom to move.

(2.) Connected with this phenomenon is that of the longitudinal crevasses seen near the edges of glaciers, and particularly where they spread out in the manner just described. Now on the gravitation theory, as remarked above, the only possible explanation of a crevasse is that the ice is bending over a convex surface, and that its upper part is thus placed in a state of tension, under which it breaks. Since, on the gravitation theory, every part of a glacier is exposed to a severe pressure from behind, this explanation does not fit very well even for transverse crevasses ; but to longitudinal crevasses it is clearly inapplicable, since the bottom of a valley is seldom or never convex in the direction of its width. On the heat theory the explanation is simple. We may suppose the heat energy communicated per square foot of surface to be about the same, whether near the middle or edge of a glacier. This energy is expended in producing an expansion throughout the whole thickness of the glacier, as described above. Hence the smaller this thickness, the greater will be the amount of expansion, and the greater therefore the net motion which results. Hence the thinner parts of a glacier will always be tending to tear themselves off from the thicker, and thus longitudinal crevasses will frequently be found.

(3.) The striæ which are so marked a feature of glacier-worn rocks become more easily explained on this theory. I have seen such striæ, even in the hard hypersthene of Skye, whicb were a considerable fraction of an inch in depth. When we consider the enormous force necessary to plough out such a furrow in hard rock, it is almost impossible to believe that it was done by the simple passage over it, once for all, of a stone imbedded in the ice. If, however, the stone descended hy a series of oscillations, so that it passed many times over the same spot, this difficulty is greatly lessened.

(4.) In conclusion I may point out that the advocates of the gravitation theory are bound to explain what becomes of the beat energy which is poured into a glacier. When the sun is shining this radiant energy is always very large, although the temperature of the air may be low. In such cases the glacier does not melt; it is perfectly clear that it must expand, as any other solid must expand under the action of heat. If so, it seems unreasonable not to hold that the gradual descent by alternate expansion and contraction must follow, as it is known to follow in the case of other materials.
On the subject of the motion of Arctic ice, Dr. Rae, F.R.S., has kindly permitted the publication of the following particulars :-

"When in Greenland, in the autumn of 1866, I was icebound at the head of one of the fiords, and slept a couple of nights at an Eskimo's house. A glacier about half a mile distant was then in full activity, the movement of which might, I believe, have been as visible to the eye as it certainly was audible to the ear.

"My own idea is that Arctic glaciers must have a downward motion more or less during the whole year, summer and winter. I believe the alternation of heat and cold-or, I should rather say, of temperature-would of itself cause motion, especially near the upper surface.

"We know that ice 2 or 3 feet or more thick contracts very considerably in a few hours by a sudden fall of 15 or 20 degrees of temperature. I have found cracks in Lake Winnipeg 3 or 4 feet wide, formed by this cause during a single night, almost stopping our sledge journey. This gap soon freezes up. Then the weather gets milder, the ice expands, and with the new additional formation is too large for the lake, and is forced up into ridges. This process goes on at every 'cold snap,' 1 alternating with milder weather. Now supposing a glacier for 10 or more feet of its depth contracts by cold, as lake ice is known to do, it will get a series of cracks probably in its longest axis, say from inland seaward; the first snowdrift will fill up these cracks or some of them, and this flling up will to some extent perform the same office as the freezing of the cracks in the lakes. The longitudinal extent of the glacier will be increased. A snowstorm always brings milder weather, which would expand the glacier, but as this expansion would naturally tend downhill, instead of up, the whole motion would be downwards. But even if the cracks I mention did not take place, the contraction by cold would pull the ice downhill, not up, whilst the expansion by increase of temperature would tend to push the glacier downhill, so that these opposite actions would produce similar effects in moving the glacier, or such part of it as could be acted upon by external temperature, downwards.

"I may also add that when a crack, however slight, is formed by contraction, the cold is admitted into the body of the glacier, and increases the contracting power or influence."

\section{SCIENTIFIC SERIALS}

Annalen der Physik und Chimie, xix., part 4.-Electrical experiments : electric pressure on solids, by G. Quincke. This paper forms a continuation to a series of experiments in electrostatics published by the author in previous numbers of the Annalen, under the title of "Electric Expansion." It is illustrated with twenty-six cuts, and will be followed by a communication on the resistance of insulating fluids to electric force.On electric disturbance at contact of gases with bodies in combustion, with four illustrations, by Julius Elste and Hans Geitel. The authors arrive at the general conclusion that all flames may be regarded as streams of hot gas, which generate negative electricity in burning electrodes introduced from without, as well as in small bodies in combustion suspended in them. -On electric vibration, and more especially on the phenomena of polarisation produced by vibratory movements, with four illustrations, by A. Overbeck.-On the dependence of gases as heat conductors on the state of the temperature, with three illustrations, by A. Winkelmann. - On the fundamental equations of E. Ketteler's theory of optics, by W. Voigt. The author shows that, so far from flowing from the principles of the doctrine of elasticity, Ketteler's fundamental equations are diametrically opposed to them.

Tre Fournal de Physique (May, 1883) contains the following original papers :-On the difference in barometrical pressure at two points in the same vertical line, by J. Jamin.-On the action of heat upon boracite and upon sulphate of potash, by E. Mallard. -On the penetration of actinic rays into the eye of man and that of vertebrates, and on their vision of uitra-violet rays, by $\mathrm{E}$. de Chardonnet.-On a new apparatus for verifying the laws governing the fall of bodies, by M. Paquet.-On an experimental demonstration of the unequal velocity of the transmission of sound in gases and solids, by F. Griveaux. cold. 